\title{
Comparative effects of plasma exchange and pyridostigmine on respiratory muscle strength and breathing pattern in patients with myasthenia gravis
}

Patrizio Goti, Alessandro Spinelli, Giampiero Marconi, Roberto Duranti, Francesco Gigliotti, Assunta Pizzi, Giorgio Scano
Section of Pulmonary

Medicine,

Department of

Internal Medicine,

Clinica Medica III

A Spinelli

R Duranti

G Scano

Department of

Neurology and

Psychiatry

G Marconi

University of Florence, Italy

Pro Juventute Don C. Gnocchi Foundation, Pozzolatico, Florence, Italy

P Goti

F Gigliotti

A Pizzi

Reprint requests to: Dr G Scano, Istituto di Dr G Scano, Istitut,
Clinica Medica III,

University of Florence, Viale University of Florence Morgagni 85,50134
Florence, Italy.

Received 31 October 1994 Returned to authors

31 January 1995

Revised version received

21 March 1995

Accepted for publication

16 June 1995
Abstract

Background - Pyridostigmine, an acetylcholinesterase antagonist, is useful in improving respiratory function in patients with myasthenia gravis. More recently, plasma exchange has been employed in myasthenia gravis because it acts presumably by removal of circulating antibodies against acetylcholine receptors. Surprisingly, comparative data on the effects of pyridostigmine and plasma exchange on lung volumes, respiratory muscle strength, and ventilatory control system in patients with myasthenia gravis are lacking.

Methods-Nine consecutive patients with grade IIb myasthenia gravis were studied under control conditions and after a therapeutic dose of pyridostigmine. In a second study the patients were re-evaluated a few days after a cycle of plasma exchange, before taking pyridostigmine. In each subject pulmonary volumes, inspiratory (MIP) and expiratory (MEP) muscle force, and respiratory muscle strength, calculated as average MIP and MEP as percentages of their predicted values, were measured. The ventilatory control system was evaluated in terms of volume (tidal volume, VT) and time (inspiratory time, TI, and total time, TTOT) components of the respiratory cycle. Mean inspiratory flow (VT/TI) - that is, the "driving" - and TI/TTOT - that is, the "timing" - components of ventilation were also measured. Results-In each patient treatment relieved weakness and tiredness, and dyspnoea grade was reduced with plasma exchange. Following treatment, vital capacity (VC) increased on average by $9.7 \%$ with pyridostigmine and by $14 \%$ with plasma exchange, and MIP increased by $18 \%$ and $26 \%$, respectively. In addition, with plasma exchange but not with pyridostigmine forced expiratory volume in one second $\left(F^{2} V_{1}\right)$ increased by $16 \%$ and MEP increased by $24.5 \%$, while functional residual capacity (FRC) decreased a little $(6 \cdot 8 \%)$. The change in respiratory muscle strength was related to change in VC $\left(r^{2}=\right.$ $0 \cdot 48)$. With plasma exchange, VT increased by $18.6 \%$ and VT/TI increased by $13.5 \%$, while neither TI nor TI/TTOT changed.
Conclusions-Plasma exchange can be used in patients with myasthenia gravis when symptoms are not adequately controlled by anticholinesterase agents. Plasma exchange increases respiratory muscle force and tidal volume due to changes in "driving" but not "timing" of the respiratory cycle.

(Thorax 1995;50:1080-1086)

Keywords: pyridostigmine, plasma exchange, myasthenia gravis, respiratory muscle strength.

Plasma exchange is regarded as an established method for treating patients with myasthenia gravis when other treatments have been ineffective. ${ }^{1-3}$ It can also be used to reduce surgical complications of thymectomy. Under these circumstances plasma exchange is thought to act by reducing circulating antibodies against the acetylcholine receptor (AChR), ${ }^{1}$ the plasma factor directly concerned in producing the disorders of neuromuscular transmission in the acquired form of the disease. ${ }^{45}$

Several studies have reported the effects of pyridostigmine, a cholinesterase inhibitor, on respiratory muscle function in patients with myasthenia gravis. ${ }^{6-8}$ Whilst hypoventilation and $\mathrm{CO}_{2}$ retention are recognised consequences from respiratory muscle weakness, there are few studies which evaluate the control of breathing in patients with chronically stable myasthenia gravis. ${ }^{8-11}$ Furthermore, there are no comparative data on the effects of pyridostigmine and plasma exchange on respiratory muscle strength and ventilatory control in patients with myasthenia gravis. We have therefore undertaken an uncontrolled study to provide an insight into these aspects of treatment of myasthenia gravis

\section{Methods}

SUBJECTS

Nine consecutive patients (three men) aged 22-68 years with moderate generalised myasthenia gravis were studied. Informed consent was given by each patient and the study was approved by the local ethics committee. Diagnosis of myasthenia gravis was defined on the basis of a clinical history of tiredness, weakness of the skeletal muscles, a decremental response to repetitive motor nerve stimulation test, and 
Table 1 Anthropometric and clinical data of patients with grade IIb myasthenia gravis

\begin{tabular}{|c|c|c|c|c|c|c|c|c|c|}
\hline \multirow[t]{3}{*}{ Patients } & \multirow[t]{3}{*}{ Age (yrs) } & \multirow[t]{3}{*}{ Sex } & \multicolumn{4}{|c|}{ Antibodies } & \multirow{3}{*}{$\begin{array}{l}\text { Duration of both disease } \\
\text { and treatment (yrs) }\end{array}$} & \multirow{3}{*}{$\begin{array}{l}S T D \\
\left(m g \times 10^{3}\right)\end{array}$} & \multirow[t]{3}{*}{ Thymectomy } \\
\hline & & & \multicolumn{2}{|c|}{ AchR } & \multicolumn{2}{|l|}{$S M$} & & & \\
\hline & & & $C$ & $P E$ & $C$ & $P E$ & & & \\
\hline 1 & 68 & M & 20 & 8 & $1: 160$ & $<1: 80$ & 6 & $21 \cdot 6$ & Yes* \\
\hline 2 & 63 & $\mathbf{M}$ & 54 & 42 & $1: 160$ & $<1: 80$ & 8 & $28 \cdot 8$ & Yes* \\
\hline 3 & 65 & $\mathbf{F}$ & 85 & 52 & - & - & 4 & $21 \cdot 6$ & No \\
\hline 4 & 57 & $\mathbf{M}$ & 44 & 25 & $1: 160$ & $<1: 80$ & 1 & $10 \cdot 8$ & Yes* \\
\hline 5 & 22 & $\mathrm{~F}$ & 35 & 15 & - & - & 1 & $10 \cdot 8$ & Yes \\
\hline 6 & 30 & $\mathrm{~F}$ & 18 & 7 & - & - & 2 & $14 \cdot 4$ & Yes \\
\hline 7 & 33 & $\mathrm{~F}$ & 15 & 10 & - & - & 4 & $21 \cdot 6$ & Yes \\
\hline 8 & 38 & $\mathrm{~F}$ & 28 & 13 & - & - & 1 & $10 \cdot 8$ & Yes \\
\hline 9 & 30 & $\mathrm{~F}$ & 64 & 29 & - & - & 5 & $27 \cdot 0$ & Yes \\
\hline
\end{tabular}

AchR = acetylcholine receptor; $S M=$ skeletal muscle; $C=$ control; $\mathrm{PE}=$ plasma exchange; $\mathrm{STD}=$ steroid total dose (daily dose $\times 180$ days $\times$ years)

* Thymoma.

a positive edrophonium chloride (Tensilon) test. ${ }^{12}$ Acetycholine receptor antibodies were available in all patients and skeletal muscle antibodies in three; all patients belonged to the IIb grade of myasthenia gravis according to Osserman's classification ${ }^{1213}$ : I, ocular myasthenia; IIa, mild generalised myasthenia; IIb, moderate generalised myasthenia; III, acute severe myasthenia; IV, late severe myasthenia. Patients had normal routine chest radiographs. All but one (patient no. 3) had undergone a thymectomy which, in three cases (nos 1, 2, and 4), was due to thymoma. Patients were being treated with oral anticholinesterase therapy (pyridostigmine, $60 \mathrm{mg}$ three or four times daily) and alternate day prednisone $(20-60 \mathrm{mg})$, which was insufficient to control symptoms. No patients fulfilled the diagnostic criteria for asthma, chronic bronchitis or emphysema as suggested by the American Thoracic Society. ${ }^{14}$ All but three patients (nos 2, 8, and 9) were non-smokers.

At the time of the study they were dyspnoeic with grade II (walking at ordinary pace on the level) to III (walking at their own pace on the level) dyspnoea. ${ }^{15}$ No patient was considered to be undernourished and mean (SD) body weight, expressed as percentage of ideal weight, ${ }^{16}$ was $95(8) \%$. The clinical data of the patients are summarised in table 1.

\section{MEASUREMENTS}

Routine spirometric tests were performed when seated as previously described. ${ }^{17}$ The normal values for lung volumes were those proposed by the European Community for Coal and Steel. ${ }^{18}$ Maximal static inspiratory (MIP) and expiratory (MEP) pressures were measured using a differential pressure transducer (Statham SC 1001; Hato Rey, Puerto Rico). The subject, comfortably seated and wearing a noseclip, performed maximal respiratory efforts at residual volume (RV) (for MIP) and at total lung capacity (TLC) (for MEP) against an obstructed mouthpiece with a small leak (internal diameter $0.6 \mathrm{~mm}$ ) to minimise oral pressure artefacts. The manoeuvres were repeated until three measurements sustained for at least one second and with less than $5 \%$ variability were recorded. The highest value obtained was used for analysis. MIP and MEP were expressed both in $\mathrm{cm} \mathrm{H}_{2} \mathrm{O}$ and as percentage of predicted value (\%pred). The predicted values for MIP and MEP were those proposed by Black and Hyatt. ${ }^{19}$
After baseline routine testing while breathing room air the ventilatory pattern was evaluated. The subjects, wearing a noseclip, were put in a comfortable supine position breathing through a mouthpiece on a circuit where the inspiratory and expiratory lines were separated by a one-way valve (Hans-Rudolph, Kansas City, Missouri, USA). Airflow was measured with a Fleisch type 3 pneumotachograph and the flow signal was integrated into the volume. From the spirogram the following breath-bybreath time and volume components of the respiratory cycle were derived: inspiratory time $(\mathrm{TI})$, expiratory time $(\mathrm{TE})$, total time of the respiratory cycle (Ттот), and tidal volume (VT). Mean inspiratory flow (VT/TI) "driving", duty cycle (TI/TTOT) "timing", respiratory frequency $(\mathrm{R} f=1 /$ TTOT $\times 60)$, and instantaneous ventilation $(\mathrm{VE}=\mathrm{VT} \times \mathrm{Rf})$ were also calculated. Expired $\mathrm{CO}_{2}\left(\mathrm{PCO}_{2}\right)$ was sampled continuously at the mouth by an infrared $\mathrm{CO}_{2}$ meter. The values for dead space and resistance of the system up to a flow of $4 \mathrm{l} / \mathrm{s}$ were $178 \mathrm{ml}$ and $0.92 \mathrm{~cm} \mathrm{H}_{2} \mathrm{O} / \mathrm{l} / \mathrm{s}$, respectively. Details of the methods have been described previously. ${ }^{820}$

The output of the $\mathrm{CO}_{2}$ meter, the flow signal, and the integrated flow signal were recorded continuously on a multichannel chart recorder. After a 10 minute adaptation period the baseline evaluation was started.

Ventilatory parameters were calculated from the data averaged from the breaths recorded over 10 minutes.

\section{PLASMAPHERESIS}

Plasma exchange was performed using a discontinuous flux cellular separator (Dideco model Progress BT 790A) and by mono-use cell apheresis (Dideco model BT 225). Perfusion of plasma substitutes consisted of: (a) $750-1000 \mathrm{ml}$ saline, (b) $500 \mathrm{ml} 10 \%$ colloidal solution of low molecular weight dextran in saline, (c) three Baxter electrolytic rehydrating Solution $(300 \mathrm{ml})$ plus $5000 \mathrm{IU}$ heparin, and (d) four $50 \mathrm{ml}$ vials of $20 \%$ human albumin added to $750 \mathrm{ml}$ saline. According to the American Society for Apheresis ${ }^{21}$ plasma volume removal was $5 \%$ body weight. Each patient had 5-9 courses of plasma exchange.

\section{DATA ANALYSIS}

Statistical analysis was performed by two way analysis of the variance and intergroup com- 
Table 2 Mean (SD) baseline pulmonary function data under control conditions (C), after pyridistogmine administration (P), and plasma exchange (PE) in patients with myasthenia gravis

\begin{tabular}{|c|c|c|c|c|c|c|c|c|}
\hline & $\begin{array}{l}V C \\
(S R)\end{array}$ & $\begin{array}{l}R F C \\
(S R)\end{array}$ & $\begin{array}{l}R V \\
(S R)\end{array}$ & $\begin{array}{l}T L C \\
(S R)\end{array}$ & $\begin{array}{l}F E V_{1} \\
(S R)\end{array}$ & $\begin{array}{l}F E V_{1} / V C \\
(\%)\end{array}$ & $\begin{array}{l}\text { MIP } \\
\text { (\%pred) }\end{array}$ & $\begin{array}{l}\text { MEP } \\
\text { (\%pred) }\end{array}$ \\
\hline $\mathrm{C}$ & $\begin{array}{r}-1.46 \\
(1.88)\end{array}$ & $\begin{array}{c}1 \cdot 21 \\
(1 \cdot 26)\end{array}$ & $\begin{array}{c}1.74 \\
(1.96)\end{array}$ & $\begin{array}{c}-0 \cdot 14 \\
(1 \cdot 17)\end{array}$ & $\begin{array}{r}-1.52 \\
(1.65)\end{array}$ & $\begin{array}{c}77 \cdot 7 \\
(16 \cdot 3)\end{array}$ & $\begin{array}{c}56 \cdot 2 \\
(19 \cdot 5)\end{array}$ & $\begin{array}{c}38 \cdot 2 \\
(18 \cdot 8)\end{array}$ \\
\hline P & $\begin{array}{c}-0.80 \\
(1.72)\end{array}$ & $\begin{array}{l}1.23 \\
(1.46)\end{array}$ & $\begin{array}{c}1 \cdot 14 \\
(2 \cdot 03)\end{array}$ & $\begin{array}{c}-0.25 \\
(1.18)\end{array}$ & $\begin{array}{c}-0.96 \\
(1.54)\end{array}$ & $\begin{array}{c}76 \cdot 8 \\
(12 \cdot 7)\end{array}$ & $\begin{array}{c}68 \cdot 5 \\
(21 \cdot 2)\end{array}$ & $\begin{array}{c}45 \cdot 2 \\
(16 \cdot 2)\end{array}$ \\
\hline PE & $\begin{array}{c}-0.35 \\
(1.56)\end{array}$ & $\begin{array}{c}0.775 \\
(1 \cdot 26)\end{array}$ & $\begin{array}{c}0.77 \\
(1.79)\end{array}$ & $\begin{array}{c}0.10 \\
(1 \cdot 22)\end{array}$ & $\begin{array}{c}-0.47 \\
(1.43)\end{array}$ & $\begin{array}{c}78 \cdot 4 \\
(13 \cdot 6)\end{array}$ & $\begin{array}{c}75 \cdot 8 \\
(21 \cdot 3)\end{array}$ & $\begin{array}{c}50 \cdot 6 \\
(16 \cdot 5)\end{array}$ \\
\hline \multicolumn{9}{|c|}{ Analysis of variance } \\
\hline $\mathrm{F}$ & $12 \cdot 71$ & 6.99 & $4 \cdot 79$ & $2 \cdot 21$ & $10 \cdot 43$ & 0.28 & $30 \cdot 35$ & 4.013 \\
\hline $\mathrm{p}$ & 0.0005 & 0.01 & 0.025 & NS & 0.002 & $0 \cdot 76$ & 0.0001 & 0.05 \\
\hline \multicolumn{9}{|c|}{ Bonferroni test ( $\mathrm{p}$ values) } \\
\hline $\begin{array}{l}\mathrm{P} v \mathrm{C} \\
\mathrm{PE} v \mathrm{C}\end{array}$ & $\begin{array}{l}<0.05 \\
<0.05\end{array}$ & $\begin{array}{l}\text { NS } \\
<0.05\end{array}$ & $\begin{array}{l}\text { NS } \\
<0.05\end{array}$ & $\begin{array}{l}\text { NS } \\
\text { NS }\end{array}$ & $\begin{array}{l}\text { NS } \\
<0 \cdot 05\end{array}$ & $\begin{array}{l}\text { NS } \\
\text { NS }\end{array}$ & $\begin{array}{l}<0.05 \\
<0.05\end{array}$ & $\begin{array}{l}\text { NS } \\
<0.05\end{array}$ \\
\hline $\mathrm{PE} v \mathrm{P}$ & NS & $<0.05$ & NS & NS & NS & NS & $<0.05$ & NS \\
\hline
\end{tabular}

$\mathrm{SR}=$ standardised residuals; $\mathrm{VC}=$ vital capacity; $\mathrm{FRC}=$ functional residual capacity; $\mathrm{RV}=$ residual volume; TLC=total lung capacity; $\mathrm{FEV}_{1}=$ forced expiratory volume in one second; $\mathrm{MIP}=$ maximal inspiratory pressure; $\mathrm{MEP}=$ maximal expiratory pressure

parisons by the Bonferroni test. Spirometric values have been reported as standardised residuals ${ }^{22}$ obtained by dividing the absolute residuals by the residual standard deviations taken from the regression equation. ${ }^{18} \mathrm{~A} p$ value of $<0.05$ was considered to be significant.

\section{PROTOCOL}

All treatment was withdrawn from the patients at least 12 hours before the study. Baseline lung function, MIP, MEP, and ventilatory pattern were measured at approximately 09.00 hours. Patients were allowed to rest between tests to avoid the effect of fatigue.

Study I: The patient was fasted and a single oral dose (120 mg) of pyridostigmine was given. Functional evaluation was repeated when patients felt better (less difficulty with chewing and swallowing, decrease in facial and limb muscle weakness), approximately 30 minutes after administration of the drug.

Study II: One to two days after the first study patients underwent the first of 5-9 courses of plasma exchange. Treatment was performed over 18-27 days, and 2-4 days after completion of the plasma exchange cycle dyspnoea grade, spirometry, respiratory muscle strength, and the pattern of breathing were re-evaluated at the same time in the morning as in the first study.

Study III: Four patients who carried out the first study on an off-steroid day were re- evaluated on either the on-steroid or off-steroid day 30 minutes and two hours after a dose of $120 \mathrm{mg}$ pyridostigmine.

\section{Results}

Baseline pulmonary function data and maximal inspiratory and expiratory pressures for patients are summarised in table 2 and fig 1 . Some patients exhibited a low vital capacity (VC) (nos $1-3,5,6)$, while functional residual capacity (FRC) (nos 1, 3, 9) and residual volume (RV) (nos $1,3,5,6)$ were mild to moderately increased in some patients. The ratio of the forced expiratory volume in one second $\left(\mathrm{FEV}_{1}\right)$ to $\mathrm{VC}$ was low in the three patients with a smoking history (nos 1, 2, 4). MEP was slightly to moderately reduced in all patients and MIP in all but two (nos 7 and 8 ).

The characteristics of the breathing pattern in the patients were compared with those of a group of 11 age-matched normal subjects (nine women of mean (SD) age $42 \cdot 1(16 \cdot 1)$ years (range 20-67)) as shown in table 3 and fig 2 . As a group the patients exhibited a more rapid and shallow breathing pattern: smaller VT, TI and greater $\mathrm{R} f$ and $\mathrm{VT} / \mathrm{TI}$. All these differences were significant $(p<0.025$ to $<0.005)$. In contrast, ventilation $(\dot{V} E)$ was similar in the patients and controls.

As shown in table 2 and fig 1 , pyridostigmine and plasma exchange both resulted in a sig-

Table 3 Breathing pattern under control conditions $(C)$, after pyridostigmine $(P)$ administration, and plasma exchange $(P E)$ in patients with myasthenia gravis. Values are mean (SD)

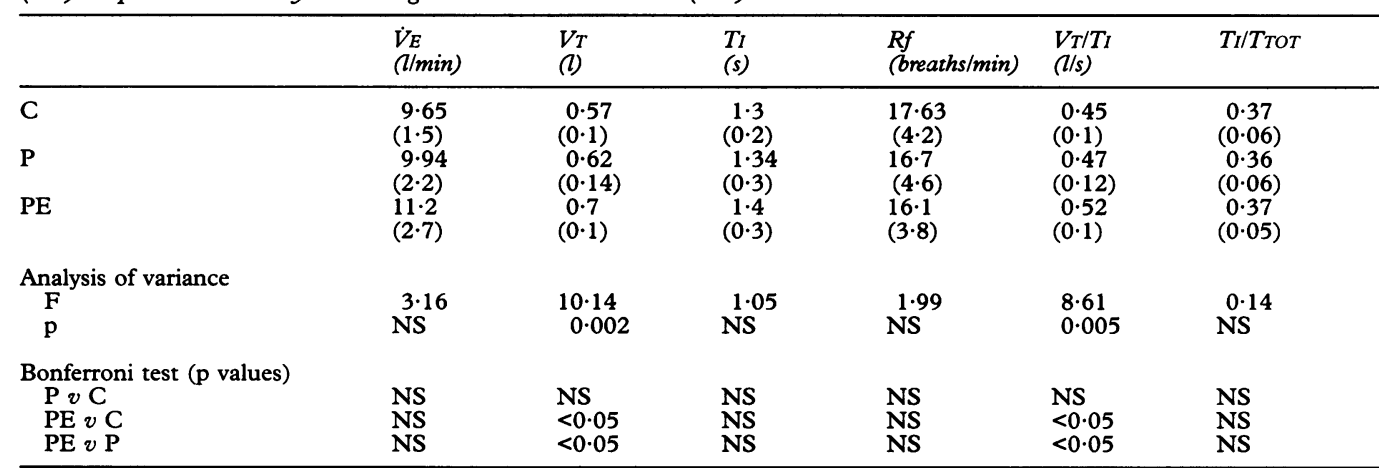

$\dot{\mathrm{V}} \mathrm{E}=$ minute ventilation; $\mathrm{VT}=$ tidal volume; $\mathrm{TI}=$ inspiratory time; $\mathrm{R} f=$ respiratory frequency; $\mathrm{VT} / \mathrm{TI}=\mathrm{mean}$ inspiratory flow; TI/TTOT $=$ timing. 

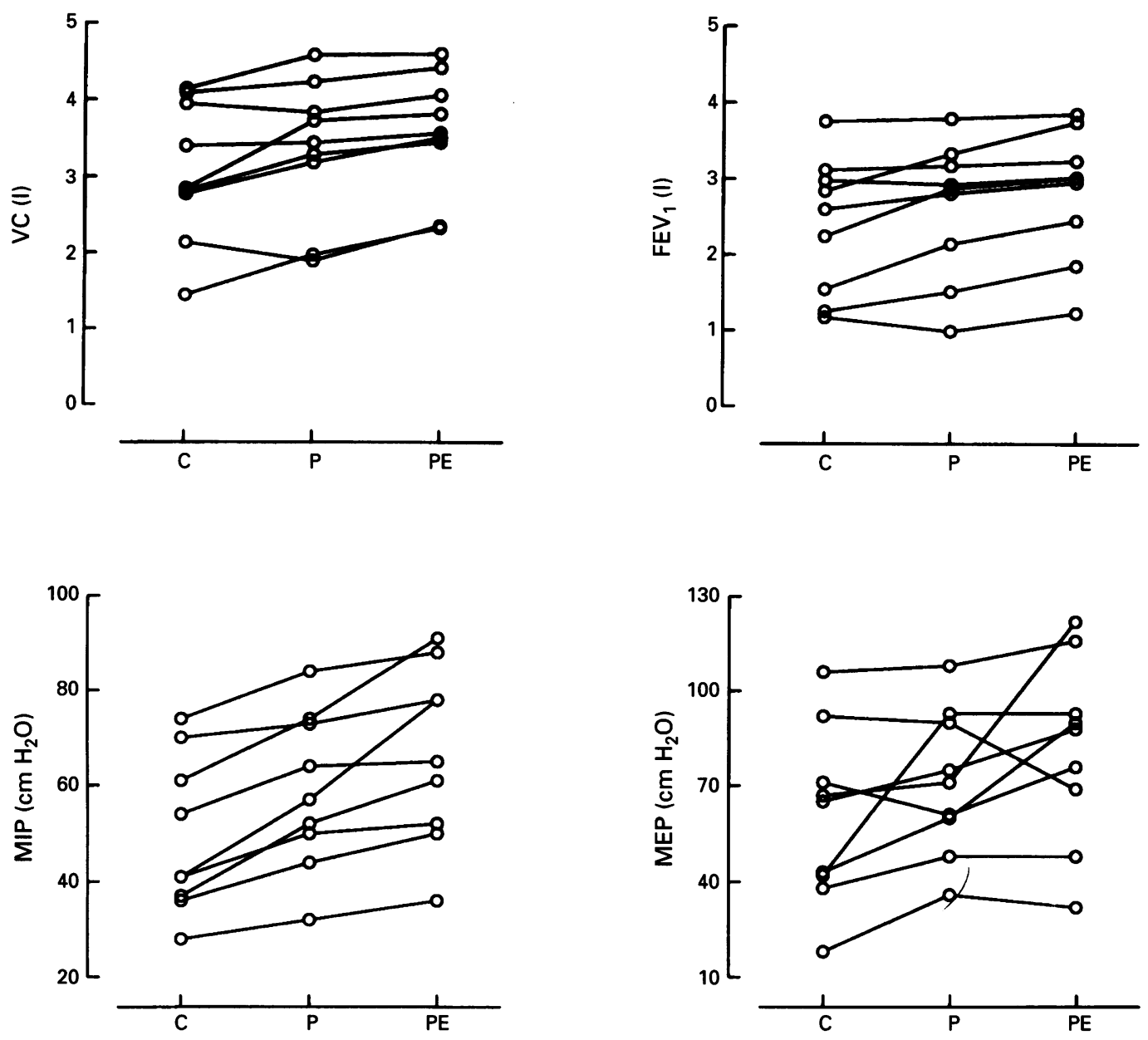

Figure 1 Individual change in vital capacity (VC), forced expiratory volume in one second (FEV), maximal inspiratory pressure (MIP), and maximal expiratory pressure $(M E P)$ after pyridostigmine $(P)$ and plasma exchange $(P E)$ in the nine patients with myasthenia gravis. $C=$ control.

nificant increase in VC $(\mathrm{p}<0.05$ for both treatments). Plasma exchange resulted in a mild but significant decrease in FRC compared with both control and pyridostigmine $(p<0.05$ for both comparisons). RV decreased and $\mathrm{FEV}_{1}$ increased with plasma exchange but not with pyridostigmine $(p<0.05$ for both variables). Both treatments resulted in a significant increase in MIP ( $p<0.05$ for both), but the increase in MIP with plasma exchange was greater than that with pyridostigmine $(p<0.05)$; in contrast, MEP increased only with plasma exchange $(p<0.05)$.

Change in respiratory muscle strength, calculated as the average \% predicted MIP and $\mathrm{MEP},{ }^{23}$ significantly related to change in VC $(r=0.696, p=0.001)$, but neither related to change in FRC nor to the duration of the disease. For each subject the calculated total dose of steroid (daily dose $\times 180$ days $\times$ years, table 1) did not relate to baseline MIP or respiratory muscle strength, nor to improvement in MIP or respiratory muscle strength with pyridostigmine or plasma exchange.

In terms of breathing pattern (table 3 and fig 2) VT and VT/Tr increased with plasma exchange compared with both the control and pyridostigmine groups ( $p<0.05$ for all comparisons). In contrast, TI/TTOT did not change with either treatment.
In each patient treatment relieved weakness and tiredness. In particular, with plasma exchange the improvement began within a few days of initiating exchange and continued for some days after the cycle ceased; dyspnoea grade lessened from III to II in some patients and from II to I (hurrying on a level or walking up a slight hill) in the others. Autoantibody levels always changed after plasma exchange (table 1).

In the third study the two hour increases in respiratory muscle strength (fig 3), VC, $\mathrm{FEV}_{1}$, and breathing pattern did not consistently differ compared with 30 minute increases recorded either on the on-steroid or off-steroid day.

\section{Discussion}

We have shown that both pyridostigmine and plasma exchange improve symptoms and respiratory function in a group of patients with grade IIb myasthenia gravis. There were increases in static and dynamic lung volumes and respiratory muscle strength for both agents, but only plasma exchange led to changes in tidal volume and mean inspiratory flow, suggesting that this modality of treatment affects the "driving" and not the "timing" of the respiratory cycle.

We have found low values for VC and high values for $R V$ in our patients with myasthenia 

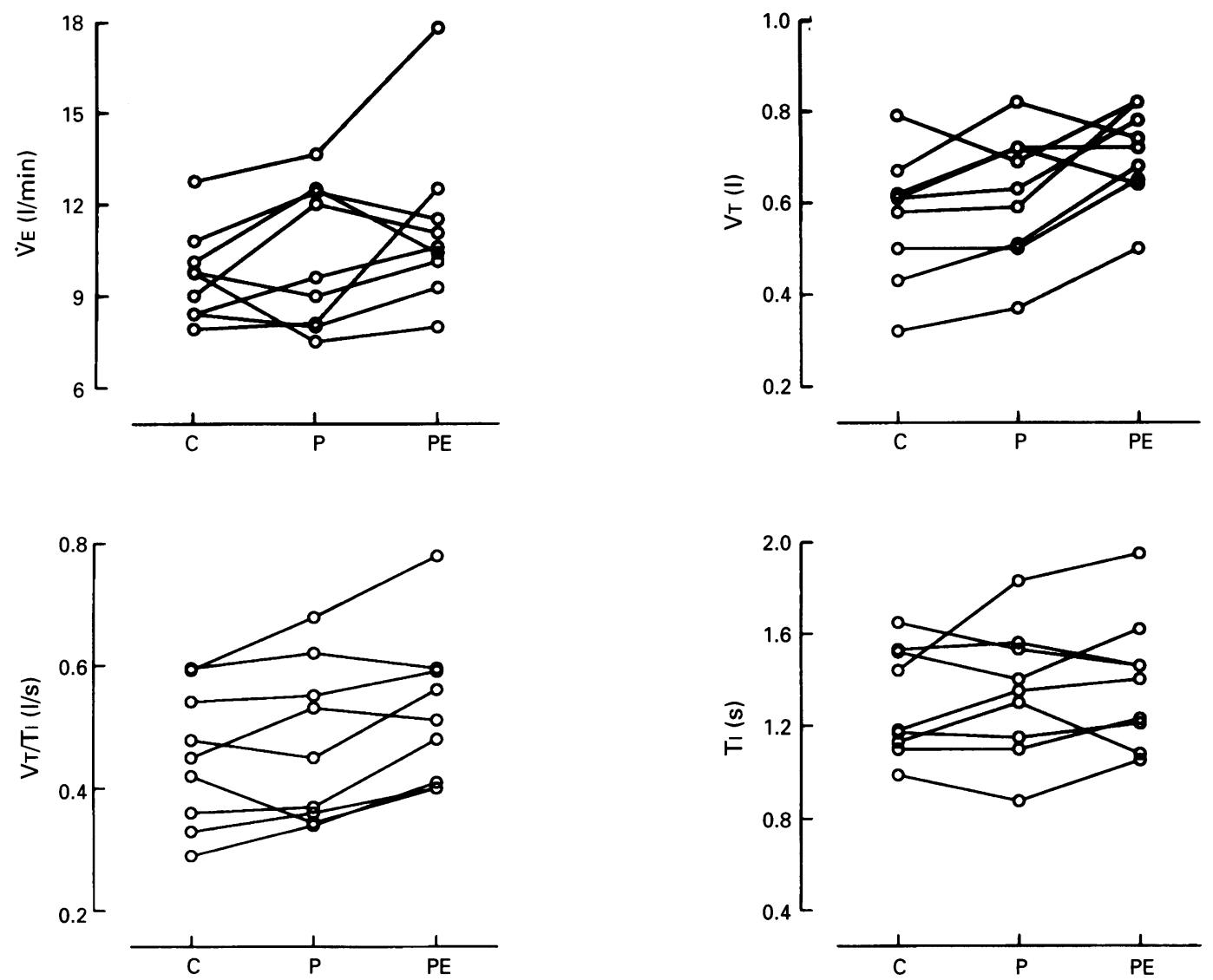

Figure 2 Individual change in minute ventilation $\left(V_{E}\right)$, tidal volume $(V T)$, mean inspiratory flow $(V T / T I)$, and inspiratory time (TI) after pyridostigmine $(P)$ and plasma exchange (PE) in the nine patients with myasthenia gravis. $C=$ control.
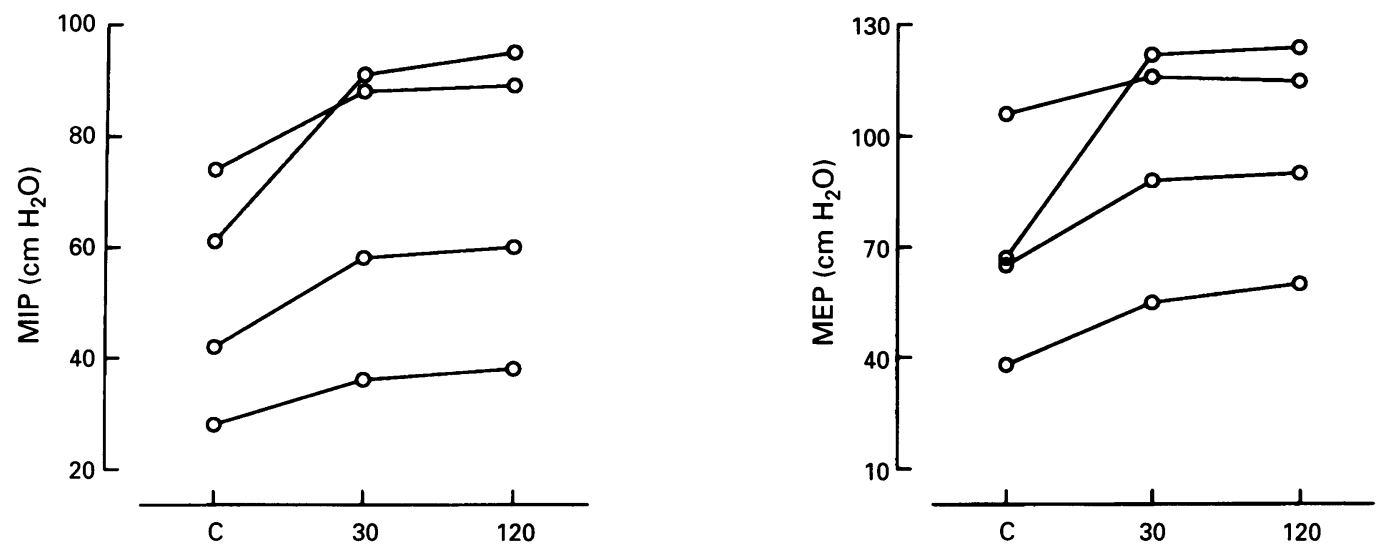

Figure 3 Individual change in maximal inspiratory pressure (MIP) and maximal expiratory pressure (MEP) 30 minutes and 120 minutes after the administration of $120 \mathrm{mg}$ pyridostigmine.

gravis which has been reported before, ${ }^{6-824}$ and may be a reflection of decreased muscle strength. ${ }^{94}$ However, we found that the increase in respiratory muscle strength with treatment accounted for about $50 \%$ of the variability in the increase in VC. This finding, together with previous data from patients with miscellaneous myopathies, ${ }^{2325}$ suggests that abnormal muscle mechanics is not the sole reason for reduced VC in patients with myasthenia gravis. In our study FRC decreased with plasma exchange but was unchanged by pyridostigmine. It has been shown that FRC was not changed by orally administered pyridostigmine,${ }^{8}$ but did increase with injected drug. ${ }^{6}$
FRC is determined by the balance between lung and chest wall forces, so the observed fall in FRC by plasma exchange could have resulted from an increased elastic recoil of the lung, a decrease in the outward recoil of the chest wall, or a combination of the two. ${ }^{25}$ We do not have data on elastic recoil of the lung to allow us to establish which factor was dominant in lowering FRC in our subjects. The fall in FRC with plasma exchange would facilitate an increase in MIP, but in our data we did not find any significant relationship between change in FRC and change in MIP.

It could be argued that examination of respiratory mechanics only 30 minutes after 
pyridostigmine administration is too early to permit maximal absorption from the gastrointestinal tract and action at the neuromuscular junction. Furthermore, the criteria for assessing benefit from oral pyridostigmine in patients with myasthenia gravis often relies solely on a patient's subjective response with improvement in chewing, swallowing, or less ocular, facial or limb weakness. We have found that two hours after oral administration of $120 \mathrm{mg}$ pyridostigmine the changes in lung volumes did not substantially differ from the changes after 30 minutes, whether recorded on the day when on or off corticosteroids. This finding agrees with the data of Shale et al. ${ }^{26}$ In terms of respiratory muscle strength, after the initial increase of $22 \%$ and $35 \%$ from control in MIP and MEP, respectively, these parameters did not increase any further, consistent with the observations of Rindgqvist and Rindgqvist, ${ }^{24}$ in whose study the maximum increase in MIP and MEP after neostigmine injection was $17 \%$ and $15 \%$ predicted respectively. Similarly, in the study by Mier-Jedrzejowicz et $a l^{7}$ MIP increased by a mean of $37 \%$ and MEP by a mean of $28 \%$ after administration of intravenous edrophonium.

The low MIP and MEP values found in our patients are likely to reflect respiratory muscle weakness - that is, the failure to generate force. In patients with myasthenia gravis inspiratory muscle weakness might depend on the defect in neuromuscular transmission and corticosteroid myopathy which is a well known adverse effect from corticosteroid treatment. ${ }^{2728}$ There is considerable evidence that abnormalities at the neuromuscular junction are the major problem in myasthenia gravis. ${ }^{29-31}$ In this context the removal of $\mathrm{AChR}$ antibodies with plasma exchange ${ }^{1}$ could account, in part, for the increase in respiratory muscle strength. The increase in MIP with pyridostigmine will in part be due to the fact that anticholinesterase antagonists increase both the action potential and force of skeletal muscle. ${ }^{30}$ With respect to the effect of corticosteroids, these may reduce respiratory muscle function in animals and man. ${ }^{20272832}$ In particular, they may affect striated muscles (IIb fibre atrophy) including respiratory muscle structure and function. ${ }^{2732}$ However, we were not able to find any relation between the total dose of corticosteroid and baseline respiratory muscle strength, or its increase with therapy. It is therefore unlikely that long term corticosteroid treatment played a part in the decrease in respiratory muscle strength noted before and after treatment. Our finding of a greater decrease in MEP than in MIP agrees with data from patients with neuromuscular disorders. ${ }^{233}$ There are no data available which compare the histological features of the diaphragm and expiratory muscles in patients with myasthenia gravis to help to explain this observation.

Because patients with myasthenia gravis vary in the time of their optimal strength with dose regimen, each patient should be studied on either their day on or off steroid. The results from our third study showed that changes in pulmonary volumes and respiratory muscle strength were indifferent to the corticosteroid regimen, and this argues against a possible undesirable influence on our results by the fact that our patients received alternate day corticosteroid therapy. In addition, our observation that the response to pyridostigmine did not differ between days on and off steroid supports this as a safe and satisfactory dose regimen for patients with myasthenia gravis.

Our patients had a rapid and shallow breathing pattern - that is, the respiratory central output was modulated via shorter inspiratory time (TI) into a tachypnoeic pattern of breathing and smaller VT. This more rapid and shallow breathing is similar to that observed in patients with several neuromuscular disorders $^{8-113435}$ including myasthenic myopathy ${ }^{29}$ with chronic ${ }^{934}$ or acute ${ }^{1011}$ ventilatory failure. In neuromuscular disorders either afferent information from weak respiratory muscles ${ }^{3637}$ and stiffened rib cage, ${ }^{34}$ or vagal afferent information from the lung, ${ }^{34}$ have been thought to act on the central inspiratory controller to terminate inspiration. The observation that $\mathrm{TI}_{\mathrm{I}}$ lay unchanged with treatment suggests that neither pyridostigmine nor plasma exchange were able to modify factors which act on the central inspiratory controller to terminate inspiration. Tidal volume (VT) increased with plasma exchange but not with pyridostigmine. There is some evidence that in patients with myasthenia gravis pyridostigmine is able to increase VT during some experimental conditions which are suspected to increase tiredness and weakness of the respiratory muscles - for example, exogenous $\mathrm{CO}_{2}$ stimulation - but not during quiet breathing. ${ }^{8}$ The reason why plasma exchange was able to increase VT in spontaneously breathing patients is likely to be complex. Rochester ${ }^{38}$ has recently hypothesised that, in order to decrease the dyspnoea sensation, patients with muscle weakness decrease the ratio of the inspiratory pressure for a given breath (Pbr) to the maximal inspiratory pressure (MIP), thereby decreasing VT. Our data showing a lower dyspnoea grade and an increased MIP are consistent with the possibility that plasma exchange brings about a greater $\mathrm{Pbr} / \mathrm{MIP}$ ratio promoting, as reported, a greater VT.

In many respiratory disorders the inspiratory drive has commonly been assessed in terms of both VT/TI and mouth occlusion pressure, ${ }^{39}$ but in patients with respiratory muscle weakness either VT/TI or mouth occlusion pressure can underestimate the effective inspiratory drive. ${ }^{3536}$ Thus, the observation in patients of a higher VT/TI is not unlikely to reflect a normal or even increased neural drive to the inspiratory muscles. The reasons for this higher drive in patients with myasthenia gravis ${ }^{8}$ and other neuromuscular disorders have been provided elsewhere. ${ }^{35-37}$ "Driving" (VT/TI) but not "timing" (TI/Tтот) was found to increase with plasma exchange. Based on the equation ${ }^{39}$

$$
\dot{V E}=\mathrm{VT} \times \mathrm{R} f=\mathrm{VT} / \mathrm{TI} \times \mathrm{TI} / \mathrm{TTOT},
$$

the increase in VT and VT/TI is the mechanism whereby $\dot{V}$ may be maintained or may increase. 
We conclude that plasma exchange can be used in patients with myasthenia gravis whose symptoms are not completely controlled by anticholinesterase agents, and that plasma exchange increases respiratory muscle force and tidal volume by a change in the "driving" but not the "timing" of the respiratory cycle.

Supported by grants from the Ministero dell'Università e della Ricera Scientifica e Tecnologica of Italy.

1 Pinching AJ, Peters DK, Newson Davies J. Remission of myasthenia gravis following plasma exchange. Lancet 1976; 25:1373-6.

2 Gracey DR, Howard FM Jr, Divertie MB. Plasmapheresis in the treatment of ventilator-dependent myasthenia gravis

3 Dau PC, Lindstrom JM, Kassel CK, Denys EH, Shev EE, Spitler LE. Plasmapheresis and immunosuppressive drug therapy in myasthenia gravis. $N$ Engl $f$ Med 1977;24: $1134-40$.

4 Tarrab-Hazdai R, Aharanov A, Silman I, Fuchs S, Abramsky $O$. Experimental autoimmune myasthenia induced in monkeys by purified acetylcholine receptors. Nature $1975 ; 256$ : 128-30.

5 Almon RR, Andrew CG, Appel SH. Serum globulin in myasthenia gravis: inhibition of a-bungarotoxin binding to myasthenia gravis: inhibition of a-bungarotoxin

6 De Troyer A, Borenstein S. Acute changes in respiratory De Troyer A, Borenstein S. Acute changes in respiratory mechanics after pyridostigmine injection in patients with

7 Mier-Jedrzejowicz AK, Brophy C, Green M. Respiratory muscle function in myasthenia gravis. Am Rev Respir Dis 1988;138:868-73.

8 Spinelli A, Marconi G, Gorini M, Pizzi A, Scano G. Contro of breathing in patients with myasthenia gravis. $A m$ Rev Respir Dis 1992;145:1359-66.

9 Newsom Davis J, Goldman M, Loh L, Casson M. Diaphragm function and alveolar hypoventilation. $Q \mathcal{F} \mathrm{Med}$ 1976;177:87-100.

10 Ferguson PT, Murphy RP, Lascelles RG. Ventilatory failure in myasthenia gravis. F Neurol Neurosurg Psychiatry 1982 45:212-22.

11 Borel CO, Tilford C, Nichols DG, Hanley DF, Traystman RJ. Diaphragmatic performance during recovery from acute ventilatory failure in Guillain-Barré

12 Kaminski MJ, Young RR. Neuromuscular and neurological disorders affecting respiration. In: Roussos C, Macklem PT, eds. The thorax. New York: Marcel Dekker, 1985 1023-87.

13 Osserman KE. Myasthenia gravis. New York: Grune and Stratton, 1958.

14 American Thoracic Society. Chronic bronchitis, asthma and pulmonary emphysema. A statement by the committee on diagnostic standards for non-tuberculous respiratory disease. Am Rev Respir Dis 1962;85:762-68.

15 Fishman AP, Ledlie JF. Dyspnea. Bull Eur Physiopathol Respir 1979;15:789-804.

16 Halpern SL, Glenn MB, Goodhart R. New height-weight tables; importance of new criteria. $\mathscr{f} A M A 1960 ; 173: 1576$ 17 Scano G, Garcia-Herreros P, Stendardi L, Degre S, De
Coster A, Sergysels R. Cardiopulmonary adaptation to exercise in coal miners. Arch Environ Health 1980;35:360-6. 18 European Community for Coal and Steel. Standardization of lung function tests. Bull Eur Physiopathol Respir 1983; 19(suppl 5):1-95.

19 Black L, Hyatt R. Maximal static respiratory pressures in generalized neuromuscular disease. Am Rev Respir Dis 1971;103:641-50.

20 Gorini M, Ginanni R, Duranti R, Spinelli A, Andreotti L, Scano $G$. Inspiratory muscle strength and respiratory drive in patients with rheumatoid arthritis. Am Rev Respir Dis 1990;142:289-94

21 Ciavarella D, Wuest D, Strauss RG, Gilcher RO, Kasprisin DO, Kiprov DD et al. Management of neurological disorders. $\mathcal{F}$ Clin Apher 1993;8:248-57.

22 Miller MR, Pincock AC. Predicted values: how we should use them? Thorax 1988;43:265-7.

23 Braun NMT, Arora NS, Rochester DF. Respiratory muscle and pulmonary function in polymiositis and other proximal myopathies. Thorax 1983;38:616-23.

24 Rindgqvist I, Rindgqvist T. Changes in respiratory mechanics in myasthenia gravis with therapy. Acta Med Scand anics in myasthen

25 De Troyer A, Borenstein S, Cordier R. Analysis of lung volume restriction in patients with respiratory muscle weakness. Thorax 1980;35:603-10.

26 Shale DH, Lane DJ, Davis CJF. Airflow limitation in myasthenia gravis. Am Rev Respir Dis 1983;128:618-21.

27 Decramer M, Stas KJ. Corticosteroid-induced myopathy involving respiratory muscles in patients with COPD or asthma. Am Rev Respir Dis 1992;146:800-2.

28 Ellis EF. Steroid myopathy. F Allengy Clin Immunol 1985; 76:431-2.

29 Rose JW, Mcfarlin DE. Myasthenia gravis. In: Sampter M, ed. Immunological diseases. Vol II, Part 4. Boston/Toronto: ed. Immunological diseases. Vol

30 Desmedt JE. The physiopathology of neuromuscular transmission and the trophic influence of motor innervation. mission and the trophic influence

31 Desmedt JE. The electrophysiological validation of myasthenia gravis. In: Albuquerque EX, Eldefrawi AT, eds. Myasthenia gravis. London: Chapman and Hall, 1983: 249-73.

32 Dekhuijzen PNR, Decramer M. Steroid-induced myopathy and its significance to respiratory disease: a known disease rediscovered. Eur Respir $\mathcal{f}$ 1992;5:997-1003.

33 Demedts M, Beckers J, Rochette F, Bulcke J. Pulmonary function in moderate neuromuscular disease without refunction in moderate neuromuscular disease without

34 Gibson GJ, Pride NB, Newsom Davis J, Loh LC. Pulmonary mechanics in patients with respiratory muscle weakness. mechanics in patients with respirato

35 De Troyer A, Pride NB. The respiratory system in neuromuscular disorders. In: Roussos C, Macklem PT, eds. The thorax. New York: Marcel Dekker, 1985:1089-21.

36 Smith PEM, Calverley PMA, Edwards RHT, Evans GA, Campbell EJM. Practical problems in the respiratory care of patients with muscular dystrophy. $N$ Engl $\mathcal{F}$ Med 1987; 316:1197-205.

37 Grinman S, Whitelaw WA. Pattern of breathing in a case of generalized respiratory muscle weakness. Chest 1983;84: $770-2$.

38 Rochester D. Respiratory muscle weakness, pattern of breathing and $\mathrm{CO}_{2}$ retention in COPD. Am Rev Respir Dis 1991;143:901-3.

39 Milic-Emili J. Recent advances in clinical assessment of control of breathing. Lung 1982;160:1-17. 